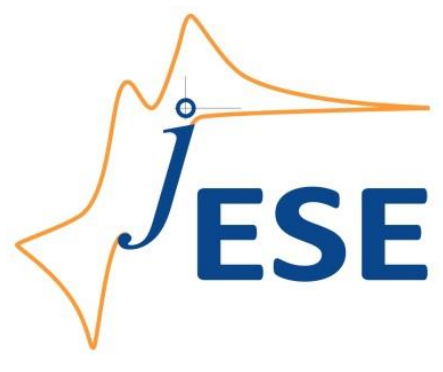

Open Access : : ISSN 1847-9286 www.jESE-online.org

Original scientific paper

\title{
Voltammetric growth of tin oxides in borate solution of pH 8.7
}

\author{
Tiago Brandão Costa ${ }^{1, \bigotimes}$, Tania Maria Cavalcanti Nogueira ${ }^{1,2}$, Ladário da Silva ${ }^{1,3}$ \\ ${ }^{1}$ Programa de Pós-Graduação em Engenharia Metalúrgica (PPGEM), Escola de Engenharia \\ Industrial Metalúrgica de Volta Redonda (EEIMVR), Universidade Federal Fluminense (UFF), \\ 27255-125 Volta Redonda, RJ, Brazil \\ ${ }^{2}$ Departamento de Engenharia Metalúrgica, EEIMVR, (UFF), 27255-125 Volta Redonda, RJ, Brazil \\ ${ }^{3}$ Departamento de Física, Instituto de Ciências Exatas (ICEx), (UFF), 27213-145 Volta Redonda, RJ, \\ Brazil
}

Corresponding author: tiagobrandao@id.uff.br, Phone: +55-2421073731

Received: February 22, 2017; Revised: May 22, 2017; Accepted: May 23, 2017

\begin{abstract}
Voltammetry has been employed to study the growth of tin oxides in buffer solution of $0.3 \mathrm{~mol} \mathrm{~L}^{-1} \mathrm{H}_{3} \mathrm{BO}_{3}+0.15 \mathrm{~mol} \mathrm{~L}^{-1} \mathrm{Na}_{2} \mathrm{~B}_{4} \mathrm{O}_{7} \cdot 10 \mathrm{H}_{2} \mathrm{O}$ ( $\mathrm{pH}$ 8.7). Voltammetric data were compared with the results of tin in a phosphate solution of $\mathrm{pH} 8.7$, presented in the previous work, in order to study the influence of these anions on the growth of tin oxides. The thicknesses of grown oxides were determined using ex-situ ellipsometric technique and the volume per charge unity of the film, $V_{f}$, was calculated for different charge densities of the film. The results showed that less dense films were obtained at higher sweep rates. Tin oxide films grown in phosphate solution at $2 \mathrm{mV} \mathrm{s}^{-1}$ were denser than those grown in borate solution at the same sweep rate. The kinetic parameters, determined applying the ohmic model, showed that there are no significant differences between the kinetics at the metal/film interface of tin in borate and tin in phosphate solutions. Despite these facts, the ionic specific resistivity for oxide film growth in borate solution were significantly higher than in phosphate solution. This result indicates that incorporation of anions occurs during the growth of the films.
\end{abstract}

\section{Keywords}

ellipsometry; tin passivation; ohmic model; voltammetry; variable ionic resistivity

\section{Introduction}

Many studies concerning the composition of tin oxides films grown by voltammetry in borate and phosphate solutions in a $\mathrm{pH}$ range of 5 to 9 are found in literature. The results showed that the composition of tin passivating film, in terms of $\mathrm{Sn}(\mathrm{II})$ and $\mathrm{Sn}$ (IV) oxides or hydroxides, depends on the growing anodic potential and different anions in solution. However, these studies do not give information about properties of tin oxides such as density and ionic resistivity [1 -11]. 
In our recent publication [12] we applied the ohmic model to describe the induced growth of tin oxides by voltammetry in phosphate buffer solution $\mathrm{pH}$ 8.7. The thicknesses of the grown oxides were measured by ex-situ ellipsometry to determine the film volume per charge unit, $V_{\mathrm{f}}$, for different charge densities of the film. This parameter makes it possible to calculate the variable ionic resistivity of the film, $\rho_{\mathrm{f}}$, during the voltammetric oxide growth, described by the ohmic model.

Tin oxide films grown at $2 \mathrm{mV} \mathrm{s}^{-1}$ become denser for higher values of charge density, near $50 \mathrm{C} \mathrm{m}^{-2}$, having $V_{\mathrm{f}}$ of $0.5 \times 10^{-10} \mathrm{~m}^{3} \mathrm{C}^{-1}$. At the same time, the representation of $\rho_{\mathrm{f}} \mathrm{vs}$. charge density of the film presents a minimum. This behavior was also found by other authors in the cases of $\mathrm{Zn}$, $\mathrm{Nb}, \mathrm{Ni}$ and galvanized steel sheets [12-17].

The ohmic model developed by D'Alkaine [12-17] presented in earlier work, describes the relation between the current density and the film overpotential during the growth of passivating film under voltammetric conditions. The following equation should be valid for peak or plateau transient conditions during voltammetric growth of a film:

$$
\eta_{\mathrm{f}, \mathrm{p}}=\frac{v}{j_{\mathrm{p}}} q_{\mathrm{f}, \mathrm{p}}
$$

In Eq. (1), $\eta_{\mathrm{f} . \mathrm{p}}$ is the overpotential across the film at the voltammetric peak, $v$ is the sweep rate, $j_{\mathrm{p}}$ is the current density at the peak and $q_{\mathrm{f}, \mathrm{p}}$ is the peak or plateau charge density.

The $q_{\mathrm{f}, \mathrm{p}}$ values can be determined considering that :

$$
q_{\mathrm{f}}=q_{\mathrm{volt}}+q_{\mathrm{o}}=\frac{1}{v} \int_{E_{i}}^{E} j_{\mathrm{a}} \mathrm{d} E+q_{\mathrm{o}}
$$

In Eq. (2), $q_{0}$ is the charge density related to the amount of film initially present at the beginning of the voltammetric growth and $q_{\text {volt }}$ is the charge density related to the amount of film which has grown on the metal surface during the voltammetric experiment. $E_{\mathrm{i}}$ is the initial potential, $E$ is the potential attained and $j_{\mathrm{a}}$ is anodic component of the current density.

The thickness of the growing film, $\ell$, is given by:

$$
\ell=V_{\mathrm{f}} q_{\mathrm{f}}
$$

In Eq. (3), $V_{\mathrm{f}}$ and $q_{\mathrm{f}}$ are respectively the volume per charge unit and the charge density related to the growing film.

The relation between the current density, $j$, and $\eta_{f}$, even at high fields, is given by:

$$
\rho_{f}=\frac{\eta_{f}}{V_{f} q_{f} j}
$$

In Eq. (4), $\rho_{\mathrm{f}}$ is the average ionic specific resistivity of the film.

In order to calculate the values of $\rho_{\mathrm{f}}$ using Eq. (4), many authors [12-17] applied the ohmic model, considering the volume per charge unit $\left(V_{f}\right)$ as the constant equal to:

$$
V_{\mathrm{f}}=\frac{M}{n F \delta}
$$

In Eq. (5), $M$ is the molar mass of the film, $\delta$ is density of the film, $n$ is the number of electrons and $F$ is the Faraday's constant.

In fact, the real values of $V_{f}$ during the voltammetric growth could only be determined by independent measurements of the film thickness. A lot of techniques are available to access such information. Generally, it can be measured [19] or calculated [20]. Ellipsometry is an interesting 
technique to be considered for the thickness measurement [21]. Ellipsometry is an indirect technique, which allows one to access layer thickness in ex-situ [12,22], and in-situ $[19,20,23]$ experiments, which is the main interest in voltammetric measurements. In an in-situ experiment it can also monitor layer growth $[19,20]$. As ellipsometry is an indirect technique, it is important to match the measured quantities, i.e., $\tan \Psi$ and $\cos \Delta$, with their counterparts in the adopted model $[21,24]$. The measured quantities are functions of the various layers and substrate refraction indexes and extinction coefficients [21].

The aim of the present work is to study the voltammetric growth of tin oxides in borate solutions $(\mathrm{pH}$ 8.7) applying the ohmic model. The thickness of the oxides grown by voltammetry will be determined by ex-situ ellipsometric measurements in order to determine experimental values of $V_{\mathrm{f}}$. The results will be compared with those obtained in previous work, in the case of tin in phosphate solution $\mathrm{pH} 8.7$ [12], to verify the influence of these anions in the voltammetric growth of tin oxides.

\section{Experimental}

\section{Electrochemical measurements}

The working electrode was made of a tin disc (PINE, $99.99 \%$ purity) with circular area of $0.5 \mathrm{~cm}^{2}$. Before the experiments, the electrode surface was polished with 600-emery paper.

The electrochemical experiments were performed using the EG\&G Princeton Applied Research Model 273A potentiostat. Solution of $0.3 \mathrm{~mol} \mathrm{~L}^{-1} \mathrm{H}_{3} \mathrm{BO}_{3}+0.15 \mathrm{~mol} \mathrm{~L}^{-1} \mathrm{Na}_{2} \mathrm{~B}_{4} \mathrm{O}_{7} \cdot 10 \mathrm{H}_{2} \mathrm{O}(\mathrm{pH}$ 8.7) was prepared from AR chemicals (Merck) and purified water (Millipore $Q$ system). The experiments were carried out in a conventional three-compartment electrolysis cell, using a platinum wire as the counter and $\mathrm{Hg} / \mathrm{Hg}_{2} \mathrm{Cl}_{2} / \mathrm{KCl}(1 \mathrm{M})$ as the reference electrode, respectively. The solution was kept at room temperature $\left(22^{\circ} \mathrm{C}\right)$.

All current and charge densities are given in terms of the geometric surface area of the analyzed samples.

Anodic voltammetries were carried out at sweep rates of 2, 5, 10, 20, 70, 100, 150, 200, 250 and $300 \mathrm{mV} \mathrm{s}^{-1}$ always on the same surface. Before each voltammetry experiment, the previously grown oxide film was reduced at constant cathodic potential equal to $-1.2 \mathrm{~V}$ during $600 \mathrm{~s}$. After this treatment, the obtained voltammograms were reproducible, indicating that surface roughness of samples was recovered.

\section{Ellipsometric measurements}

The ex-situ ellipsometric measurements were made using a SEMILAB spectroscopic ellipsometer, model SOPRA GES 5E, equipped with a Xe lamp, over the spectrum range of $195-1,000 \mathrm{~nm}$. The measurements were made in air and at room temperature (roughly $22{ }^{\circ} \mathrm{C}$ ) with incident angle of $75^{\circ}$. The thicknesses of the oxide films were obtained by analyzing the measured ellipsometric spectra through the Drude and Gauss model [16].

\section{Results and discussion}

Figure 1 presents the voltammogram for tin in the borate solution. A cathodic peak $\left(c_{1}\right)$ is related to the reduction of the tin oxide. In the anodic scan, two anodic peaks ( $a_{1}$ and $a_{2}$ ) appear related to the tin oxides growth. At near $1.5 \mathrm{~V}$ the oxygen evolution process begins. In view of this result, the potential of $-1.2 \mathrm{~V}$ was chosen to reduce the previously grown oxide film before each voltammetric experiment, as explained in the Experimental section. 


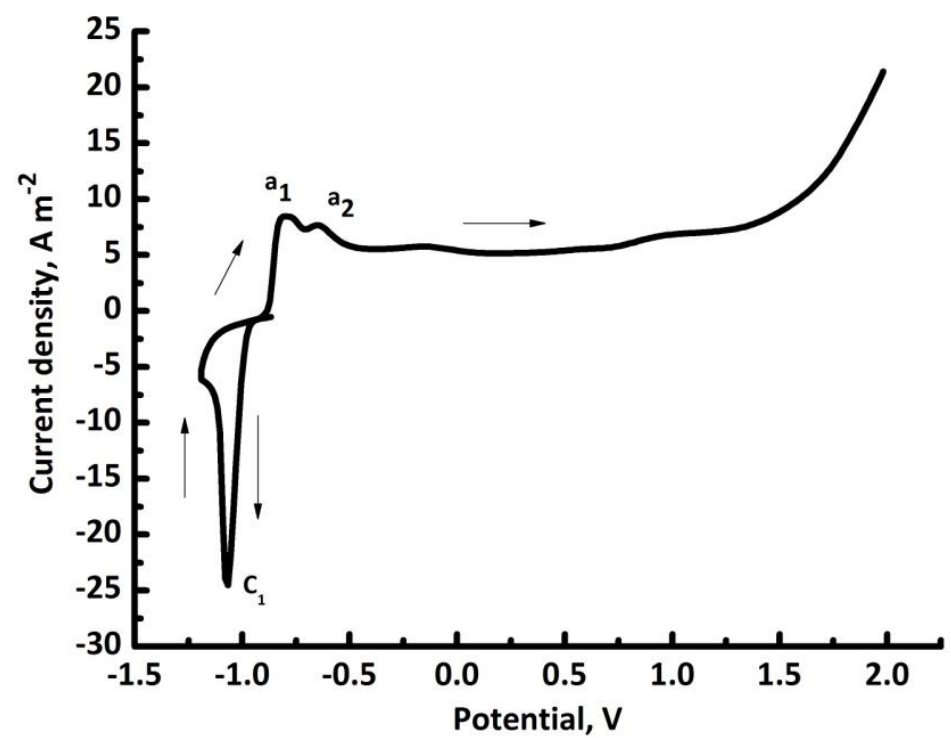

Figure 1. Potentiodynamic curve for tin in solution borate, $\mathrm{pH} 8.7$, at sweep rate $100 \mathrm{mV} \mathrm{s}^{-1}$.

Figure 2 presents the anodic voltammograms for tin oxide growth at different sweep rates. The overpotential values in the film at peak condition $\left(\eta_{f, p}\right)$ were calculated using the Eq. (1). The values of $q_{\text {volt }}$ and $j_{\mathrm{p}}$ were determined from the voltammograms. The value of $q_{0}$ in Eq. (2) was first considered to be equal to $0.0 \mathrm{C} \mathrm{m}^{-2}$. The curve $j$ vs. potential at the metal/film interface $\left(E_{\mathrm{m} / \mathrm{f}}\right)$, also shown in this Figure, is obtained after correction of the ohmic drop through the film at the peak potential $\left(E_{\mathrm{p}}-\eta_{\mathrm{f}, \mathrm{p}}\right)$.

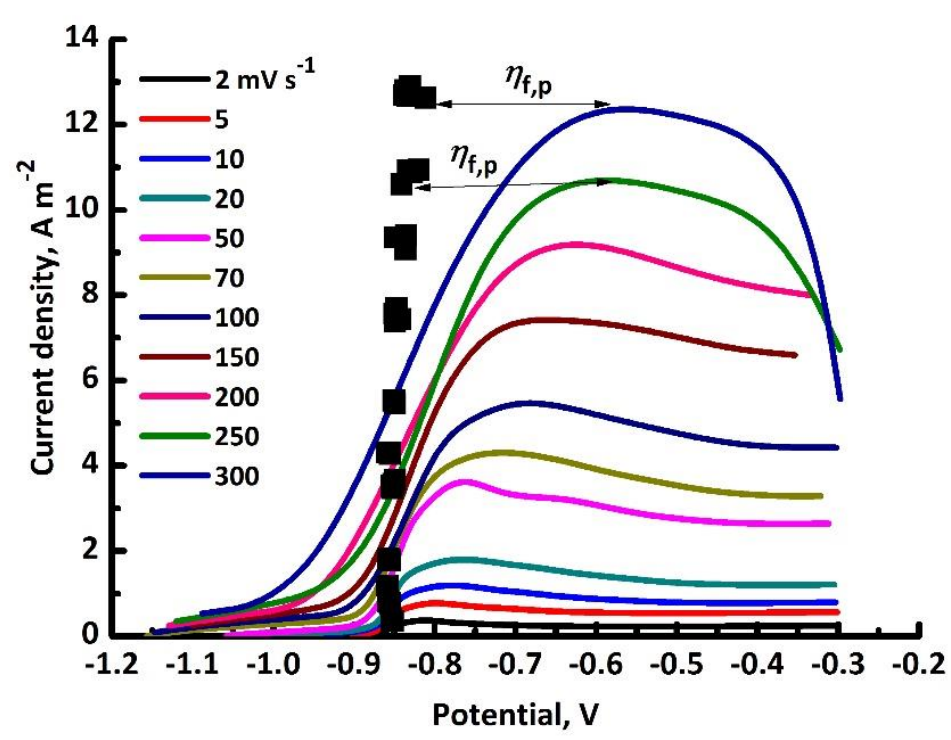

Figure 2. Voltammetric growth of tin oxide film in borate solution at different scan rates, together with the plot of the calculated $\mathrm{j} v \mathrm{vs}\left(\mathrm{E}_{p}-\eta_{f, p}\right)$ relation at the metal/film interface,

$$
\text { considering } \mathrm{q}_{0}=0.0 \mathrm{Cm}^{-2}(\mathbf{m}) \mathrm{E}_{p}-\eta_{f, p}
$$

The Tafel plot of the curve $j$ vs. $E_{\mathrm{m} / \mathrm{f}}$ in Figure 2 is represented in Figure 3.

In Figure 4, the value of $q_{0}$ was taken equal to $0.8 \mathrm{C} \mathrm{m}^{-2}$, in order to provide the best straight line region of the Tafel plot giving a Tafel slope $\left(b_{\mathrm{a}}\right)$ equal to $41.14 \mathrm{mV} \mathrm{dec}^{-1}$.

By using Eq. (6) [25]: 


$$
b_{\mathrm{a}}=\frac{\alpha_{\mathrm{m} / \mathrm{f}} n F}{R T}
$$

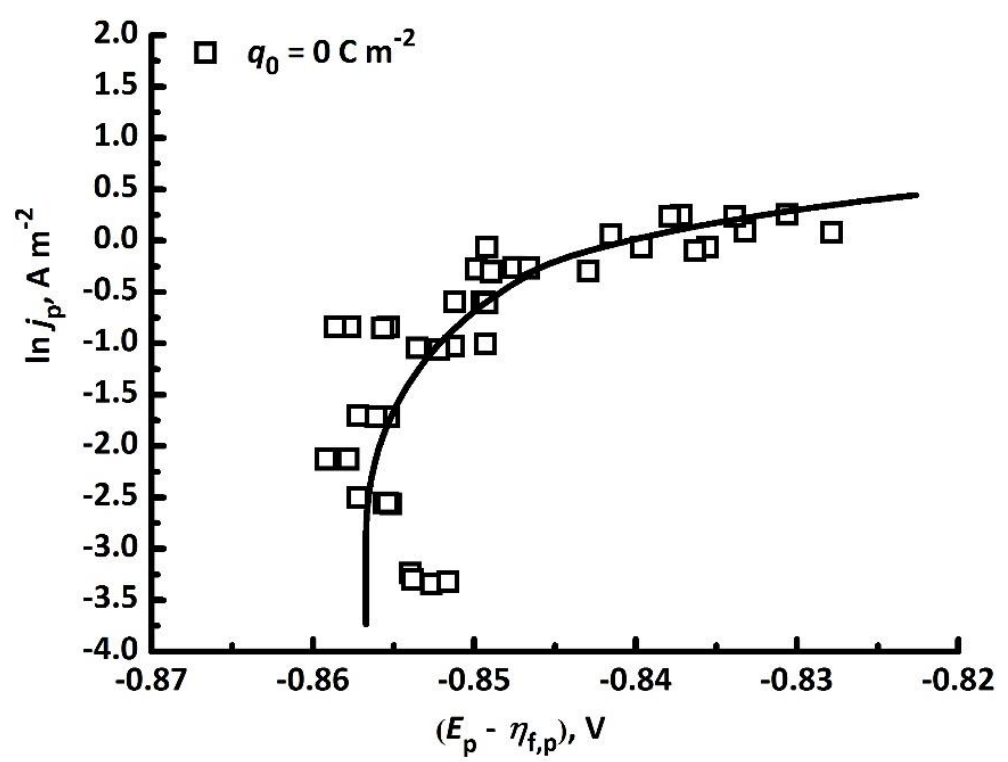

Figure 3. Tafel plot at tin/oxide interface in borate solution.

In Eq. (6), $\alpha_{\mathrm{m} / \mathrm{f}}$ is the transfer coefficient, $n$ is the number of electrons, $F$ is Faraday's constant, $R$ is gas constant and $T$ is temperature.

The product $\left(\alpha_{\mathrm{m} / \mathrm{f}} n\right)$ at the metal/film interface turned to be 1.05 .

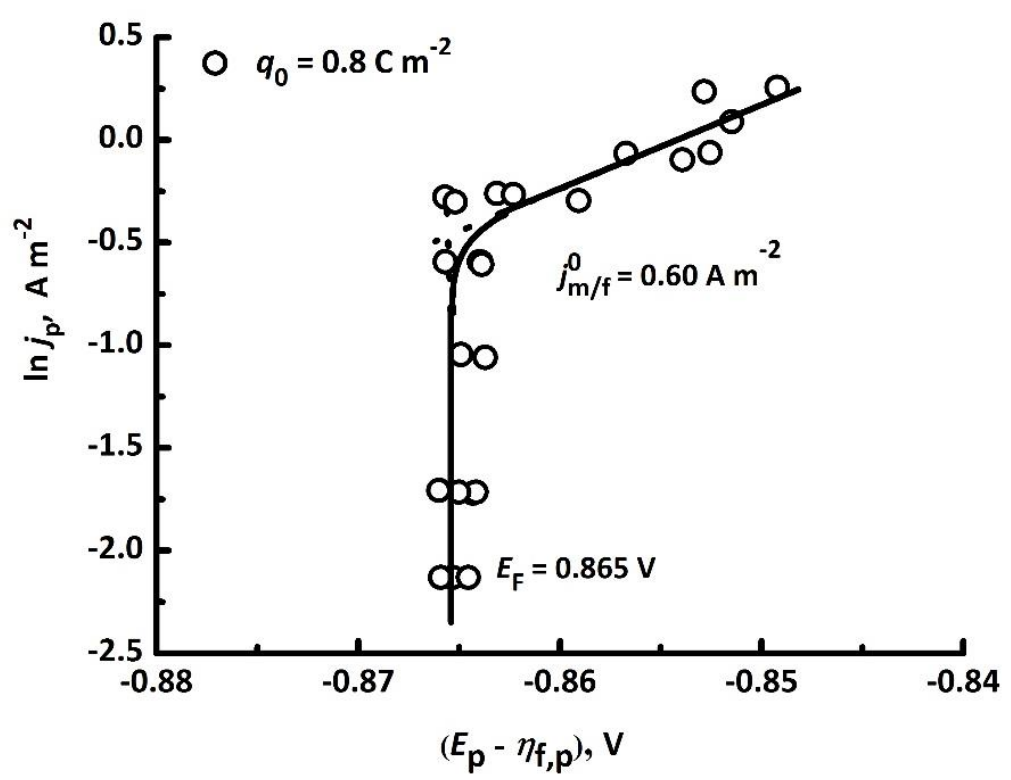

Figure 4. Tafel plot at tin/oxide interface in borate solution, considering $\mathrm{q}_{0}=0.8 \mathrm{C} \mathrm{m}^{-2}$.

The value of $j_{\mathrm{m} / \mathrm{f}}^{0}$, obtained as shown in Figure 4, is equal to $0.60 \mathrm{~A} \mathrm{~m}^{-2}$. These values should be compared with 1.07 and $1.0 \mathrm{~A} \mathrm{~m}^{-2}$, respectively, obtained in the case of phosphate solution [12]. These results suggest that there are no significant differences between the kinetics in the two studied metal /film interfaces.

From the Tafel plot of Figure 4 the corrected curve $j v s$. $E_{\mathrm{m} / \mathrm{f}}$, was obtained. Figure 5 illustrates these results. The anodic voltammograms are also shown in the same Figure.

Figure 6 Present the variation of the peak charge density up to the peak potential $\left(q_{\mathrm{f}, \mathrm{p}}\right)$ with $v$. 


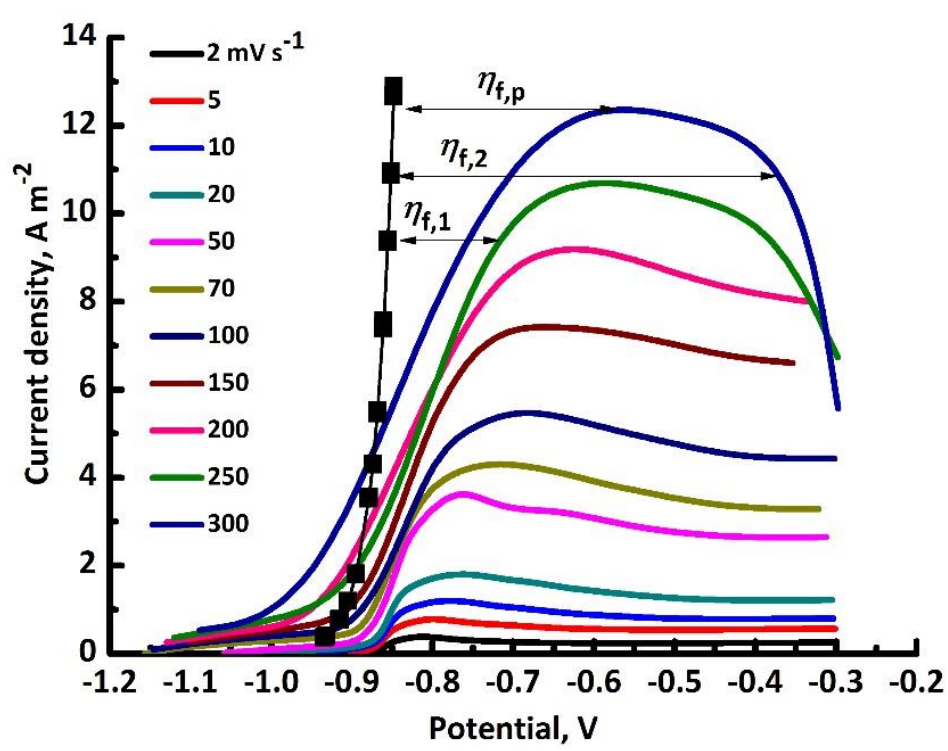

Figure 5. Voltammetric growths of tin oxide film in borate solution at different scan rates, together with the plot of the calculated $\mathrm{j} v \mathrm{vs}\left(\mathrm{E}-\eta_{f, p}\right)$ relation at the metal/film interface, considering $\mathrm{q}_{0}=0.8 \mathrm{C} \mathrm{m}^{-2}$ and Figure 4 . ( $(\mathbf{m}) \mathrm{E}_{p}-\eta_{f, p}$

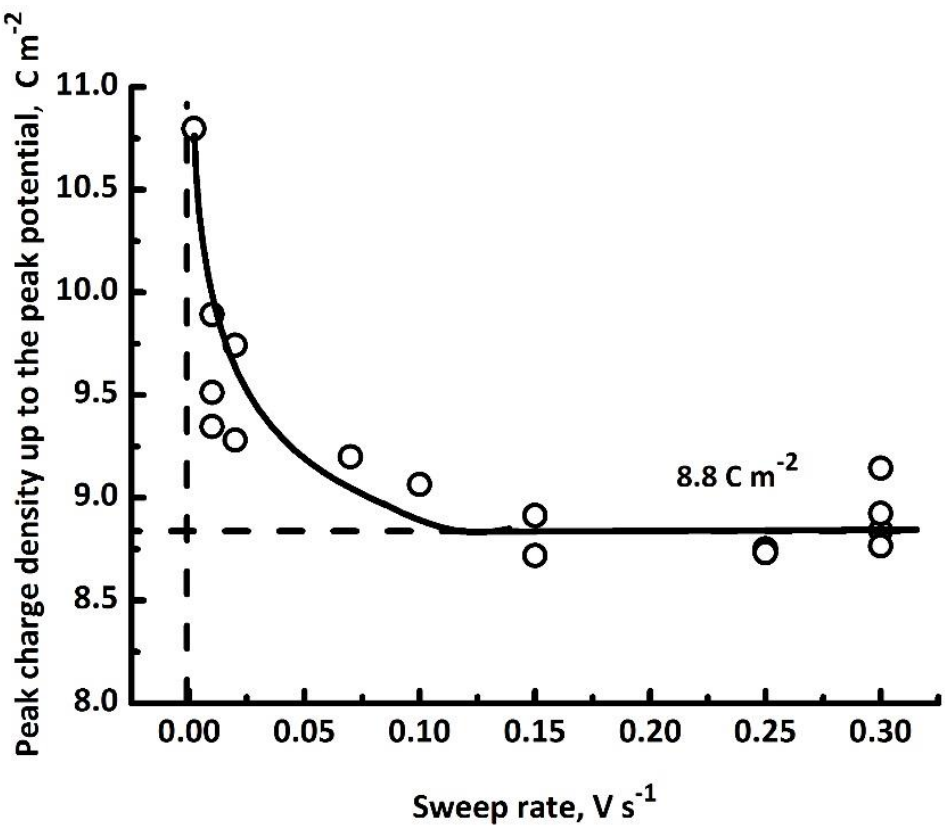

Figure 6. Peak charge density up to the peak potential $\left(\mathrm{q}_{f, p}\right)$ vs. the sweep rate.

This result shows that the charge required for film growth up to peak potential becomes constant for sweep rates higher than $0.10 \mathrm{~V} \mathrm{~s}^{-1}$. According to D'Alkaine [13] this means that the parameters related to the film (aging phenomenon) become independent of the growing conditions for sweep rates higher than $0.10 \mathrm{~V} \mathrm{~s}^{-1}$. In view of this fact, the variable ionic resistivities were studied for 2 and $100 \mathrm{mV} \mathrm{s}^{-1}$.

Figure 5 can be used to determine the overpotential at the film $\left(\eta_{f}\right)$ for any growing condition of the film beyond the peak condition, by calculating the difference of the potential in the voltammogram at any sweep rate and the potential in the curve $j v s$. $E_{\mathrm{m} / \mathrm{f}}$ for a given current density. This is shown in Figure 5 for the voltammograms at 250 and $300 \mathrm{mV} \mathrm{s}^{-1}$. 
By calculating $\eta_{\mathrm{f}}$ values for each potential, it is possible to determine the ionic specific resistivity of the film $\left(\rho_{f}\right)$ and its variation with $E$ and $v$, for each voltammetric curve using Eq. (4).

The real values of $V_{f}$ during the voltammetric growth can be determined by an independent way of measuring the thickness of the film according to the following equation:

$$
V_{\mathrm{f}}=\frac{\ell A}{q_{\mathrm{f}}}
$$

In Eq. (7), $\ell$ is thickness and $A$ is surface area the working electrode.

In the present work, the thicknesses of oxides films grown at 2 and $100 \mathrm{mV} \mathrm{s}^{-1}$ were measured by ex-situ ellipsometry. Figure 7 and Figure 8 present the final potential $\left(E_{f}\right)$ of each voltammetry experiment performed at 2 and $100 \mathrm{mV} \mathrm{s}^{-1}$, respectively.

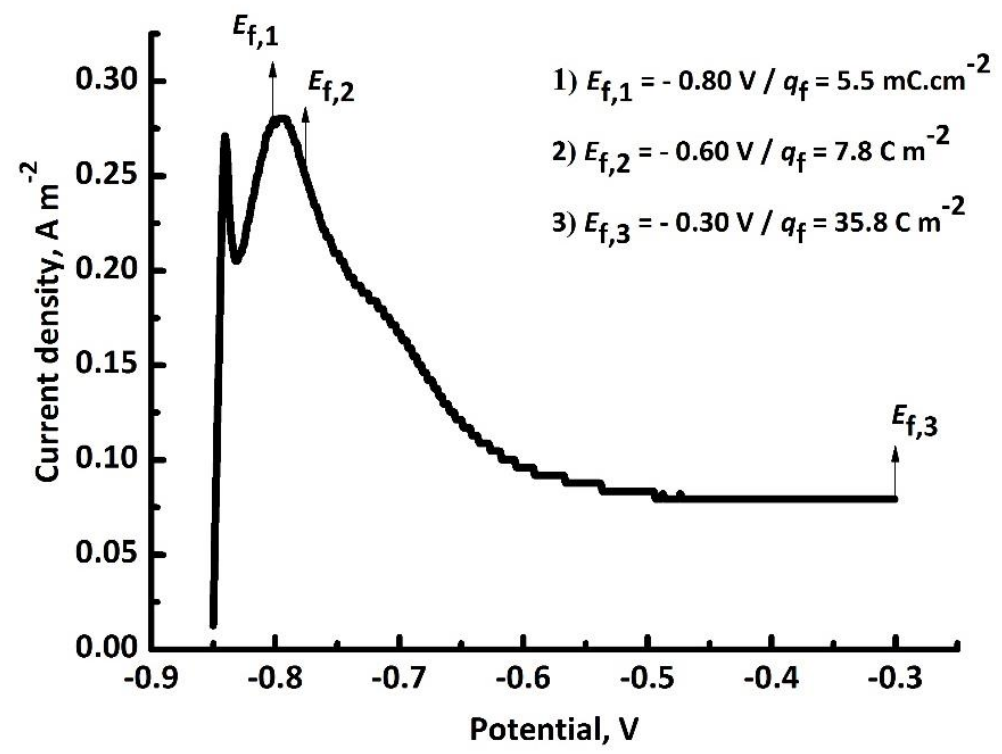

Figure 7. Voltammetric growth of tin oxide films in borate solution, at $2 \mathrm{mV} \mathrm{s}^{-1}$, together with indication of the final potential, $\mathrm{E}_{f}$, and corresponding film charge density values.

As pointed out before, spectroscopic ellipsometer was used to obtain thicknesses of tin oxide films grown at distinct values of charge density. Measured and modelled values of $\tan \Psi$ and $\cos \Delta$ vs. wavelength presented good fitting parameters with for $R^{2}>0.97$.

The average thicknesses obtained for charge densities grown in borate solution, at 2 and at 100 $\mathrm{mV} \mathrm{s}^{-1}$ are shown in Table 1 and Table 2, respectively. In Table 1 and Table 2, the values of the final potential, $E_{\mathrm{f}}$, charge density of the film, $q_{\mathrm{f}}, R^{2}$, standard deviations of the average thickness values and standard deviations $(\sigma)$. Data in Table 1 clearly show that for greater $E_{f}$ and $q_{\mathrm{f}}$, greater average film thickness is obtained.

Table 1. Final potentials at $2 \mathrm{mV} \mathrm{s}^{-1}$, charge densities, thicknesses, average thicknesses and statistical results of calculations

\begin{tabular}{ccccccccccccccc}
\hline$E_{\mathrm{F}} / \mathrm{V}$ & $q_{\mathrm{f}} / \mathrm{C} \mathrm{m}^{-2}$ & \multicolumn{1}{c}{$\ell / \mathrm{nm}$} & \multicolumn{1}{c}{$R^{2}$} & Average thicknesses, $\mathrm{nm}$ & $\sigma$ \\
\hline-0.80 & 5.5 & 3.1 & 3.3 & 3.5 & 3.3 & 3.3 & 4.2 & 3.4 & 3.3 & 0.971 & 3.43 & 0.311 \\
\hline-0.60 & 7.8 & 5.0 & 5.0 & 4.2 & 5.0 & 4.4 & 5.1 & 5.0 & 4.4 & 0.992 & 4.76 & 0.338 \\
\hline-0.30 & 35.8 & 5.6 & 5.6 & 5.8 & 5.8 & 5.8 & 5.5 & 5.7 & 5.9 & 0.991 & 5.71 & 0.127 \\
\hline
\end{tabular}




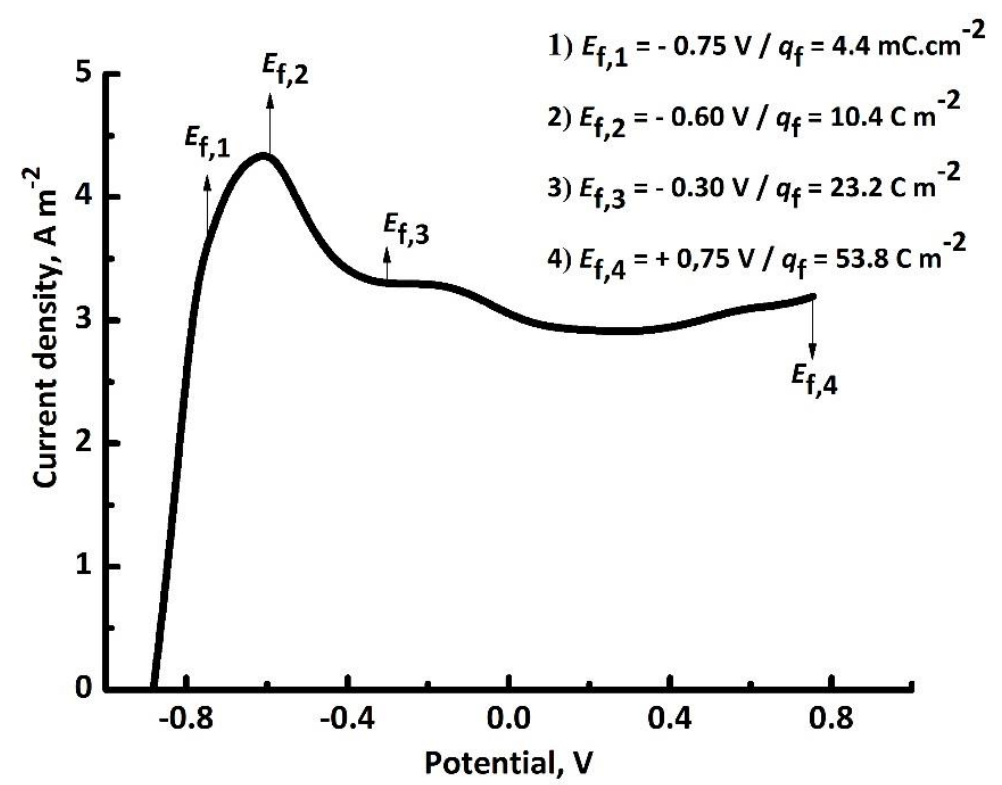

Figure 8. Voltammetric growth of tin oxide films in borate solution, at $100 \mathrm{mV} \mathrm{s}^{-1}$, together with indication of the final potential, $\mathrm{E}_{f}$, and corresponding film charge density values.

Table 2. Final potentials at $100 \mathrm{mV} \mathrm{s}^{-1}$, charge densities, thicknesses, average thicknesses and statistical results of calculations

\begin{tabular}{cccccccccccccc}
\hline$E_{\mathrm{F}} / \mathrm{V}$ & $q_{\mathrm{f}} / \mathrm{Cm}^{-2}$ & \multicolumn{1}{c}{$\ell / \mathrm{nm}$} & & \multicolumn{1}{c}{$R^{2}$} & Average thicknesses, $\mathrm{nm}$ & $\sigma$ \\
\hline-0.75 & 4.4 & 4.4 & 4.3 & 4.8 & 4.2 & 4.8 & 4.0 & 4.2 & 4.3 & 0.992 & 4.35 & 0.274 \\
\hline-0.60 & 10.4 & 6.4 & 7.3 & 6.6 & 7.3 & 6.6 & 7.3 & 6.3 & 7.5 & 0.983 & 6.90 & 0.455 \\
\hline-0.30 & 23.2 & 7.1 & 7.6 & 7.5 & 7.3 & 7.3 & 7.5 & 7.3 & 7.5 & 0.980 & 7.40 & 0.154 \\
\hline 0.75 & 53.8 & 9.0 & 8.6 & 9.4 & 8.7 & 9.0 & 8.1 & 9.4 & 8.1 & 0.988 & 8.79 & 0.478 \\
\hline
\end{tabular}

Figure 9 presents the average thicknesses obtained for charge densities grown at 2 and $100 \mathrm{mV} \mathrm{s}^{-1}$. The results for tin in phosphate solution at $2 \mathrm{mV} \mathrm{s}^{-1}$ are also presented in this same Figure.

It is possible to observe that the values of thickness of tin oxides grown at $100 \mathrm{mV} \mathrm{s}^{-1}$ in borate solution are higher than those grown at $2 \mathrm{mV} \mathrm{s}^{-1}$. This fact shows that less dense films are obtained at higher sweep rates. In comparison with the results of tin in phosphate solution at $2 \mathrm{mV} \mathrm{s}^{-1}$, it is interesting to notice that the films grown in this last solution are denser.

Using the experimentally found values of average thicknesses, Eq. (7) was applied and $V_{f}$ was determined for the values of charge density of voltammetry grown films at 2 and $100 \mathrm{mV} \mathrm{s}^{-1}$. The results are shown in Table 3.

Table 3. Film volume per charge unit obtained from the thicknesses measurements of tin oxide films for different charge densities and sweep rates.

\begin{tabular}{cccccc}
\hline \multicolumn{5}{c}{$2 \mathrm{mV} \mathrm{s}^{-1}$} & \multicolumn{3}{c}{$100 \mathrm{mV} \mathrm{s}^{-1}$} \\
\hline$q_{\mathrm{f}} / \mathrm{C} \mathrm{m}^{-2}$ & $\ell / \mathrm{nm}$ & $V_{\mathrm{f}} / 10^{-10} \mathrm{~m}^{3} \mathrm{C}^{-1}$ & $q_{\mathrm{f}} / \mathrm{C} \mathrm{m}^{-2}$ & $\ell / \mathrm{nm}$ & $V_{\mathrm{f}} / 10^{-10} \mathrm{~m}^{3} \mathrm{C}^{-1}$ \\
\hline 5.5 & 3.43 & 6.24 & 4.4 & 4.35 & 9.89 \\
\hline 7.8 & 4.76 & 6.10 & 10.4 & 6.90 & 6.63 \\
\hline 35.8 & 5.71 & 1.59 & 23.2 & 7.40 & 3.19 \\
\hline & & & 53.8 & 8.79 & 1.63 \\
\hline
\end{tabular}

Figure 10 presents the values of $V_{f}$ vs. charge density of the film obtained in borate solution, together with the values of $V_{f}$ obtained in phosphate solution [12] and the values of $V_{f}$ calculated by Eq. (7), considering $\mathrm{SnO}$ and $\mathrm{SnO}_{2}$. 


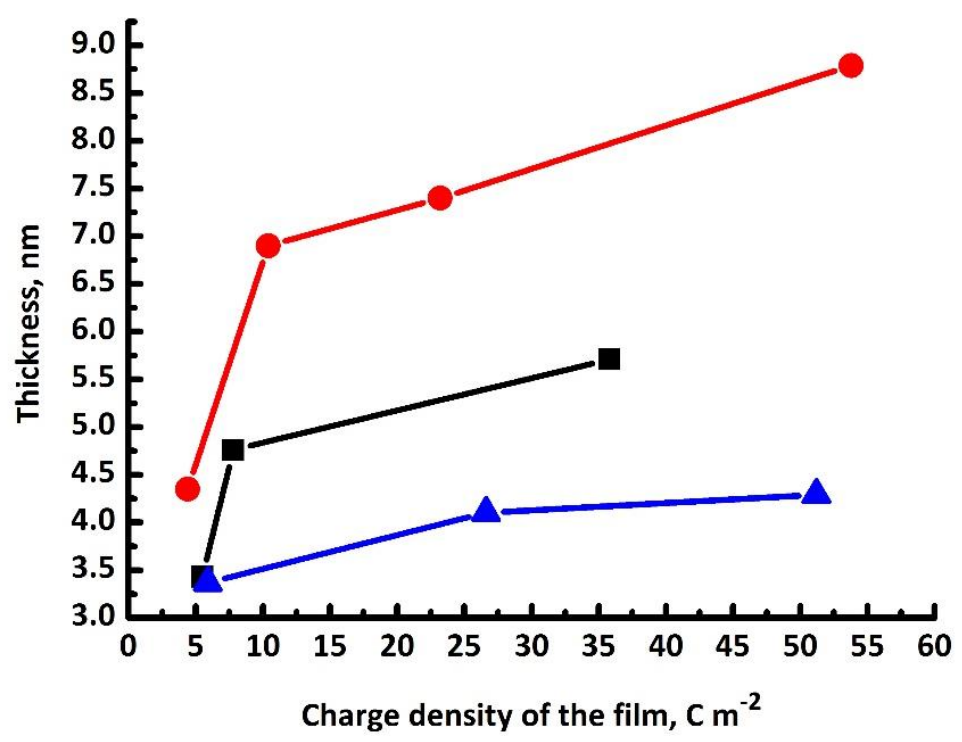

Figure 9. Thickness vs. charge density of the films grown in borate solution at (घ) 2,

(•) $100 \mathrm{mV} \mathrm{s}^{-1}$ and in phosphate solution at (A) $2 \mathrm{mV} \mathrm{s}^{-1}$

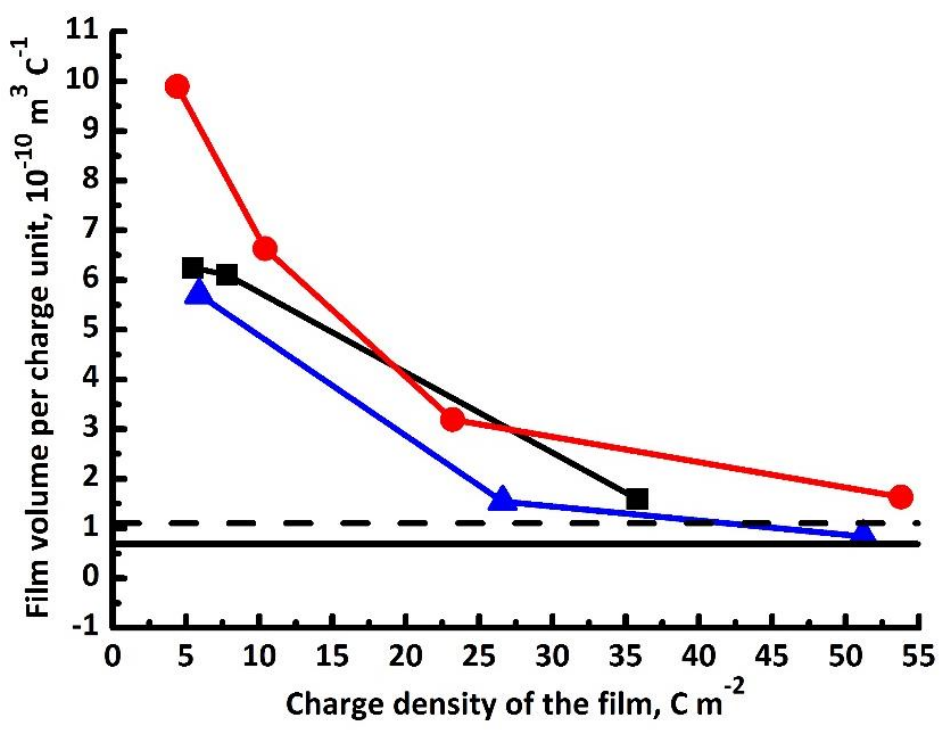

Figure 10. Film volume per charge unit for different values of charge density. (घ) Experimental $\mathrm{V}_{f}$ for tin oxide grown at $2 \mathrm{mV} \mathrm{s}^{-1}$ in borate solution, (•) Experimental $\mathrm{V}_{f}$ for tin oxide grown at $100 \mathrm{mV} \mathrm{s}^{-1}$ in borate solution, (A)Experimental $\mathrm{V}_{f}$ for tin oxide grown at $2 \mathrm{mV} \mathrm{s}^{-1}$ in phosphate solution, $(---) \mathrm{V}_{f}=1.08 \times 10^{-10} \mathrm{~m}^{3} \mathrm{C}^{-1}$ (considering SnO) and $(-) \mathrm{V}_{f}=0.568 \times 10^{-10} \mathrm{~m}^{3} \mathrm{C}^{-1}$ (considering $\mathrm{SnO}_{2}$ ).

Data in Table 3 and Figure 10 show that, for borate and phosphate [12] solutions, the values of $V_{f}$ significantly decrease until $50 \mathrm{C} \mathrm{m}^{-2}$ of charge density of the film is achieved. This result shows that the film is less dense for lower values of charge density and becomes denser as the thickness increases. This behavior suggests that changes in the composition of the film are taking place as the potential turns more anodic, approximating the values of $\mathrm{V}_{\mathrm{f}}$ considering $\mathrm{SnO}$ and $\mathrm{SnO}_{2}$. The influence of the final potential in changes in composition of the film, in terms of Sn(II) and Sn(IV), was already mentioned by other authors [1-11].

By introducing experimentally determined $V_{f}$ values into Eq. (4) the values of $\rho_{f}$ can be calculated. Figure 11 illustrates the results obtained using the values of charge density in Table 3 for the case of the voltammetry experiment at 2 and $100 \mathrm{mV} \mathrm{s}^{-1}$ in borate solution.

As can be observed in the case of sweep rate $2 \mathrm{mV} \mathrm{s}^{-1}, \rho_{\mathrm{f}}$ passes through a minimum (justifying the maximum in current densities). This behavior was also found in previous work [1] and in voltammetric 
oxide film growth of $\mathrm{Zn}, \mathrm{Nb}, \mathrm{Ni}$ and galvanized steel sheets [13-17]. According to the theory this happens because the passage of current in the film of initial thickness $\left(q_{0}\right)$ generates injection of specific defects, what resulted in decrease of $\rho_{\mathrm{f}}$ (inversely proportional to concentration of defects) [13-17].

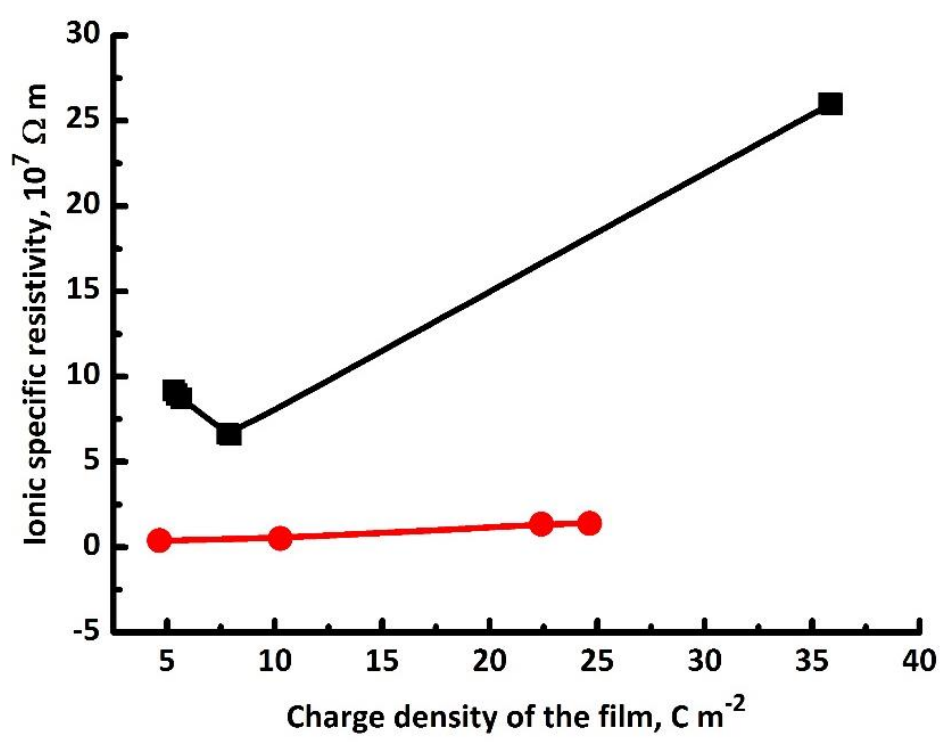

Figure 11. Ionic specific resistivity vs. charge density of the film for sweep rate equal to $2 \mathrm{mV} \mathrm{s}^{-1}$ (घ) and $100 \mathrm{mV} \mathrm{s}^{-1}(\bullet)$ in borate solution.

Increase of recombining specific defects (interstitial and cationic vacancies) in the film ends up by generating the recombination reaction (interstitial cation + cationic vacancy $\rightarrow$ cationic net), and making $\rho_{\mathrm{f}}$ to increase again [13-17].

In the case of the voltammetry at $100 \mathrm{mV} \mathrm{s}^{-1}$ the values of $\rho_{\mathrm{f}}$ are lower than the values of $\rho_{\mathrm{f}}$ in the voltammetry at $2 \mathrm{mV} \mathrm{s}^{-1}$. This can be explained considering that at higher sweep rates the injection of defects occurs faster than their recombination. It is also interesting to point out that this phenomenon generates less dense films, as can be observed in Figure 9.

Figure 12 presents the values represented in Figure 11 together with the values of $\rho_{\mathrm{f}} v s$. charge density of the film found in previous work in the case of tin in phosphate solution for sweep rate equal to $2 \mathrm{mV} \mathrm{s}^{-1}$.

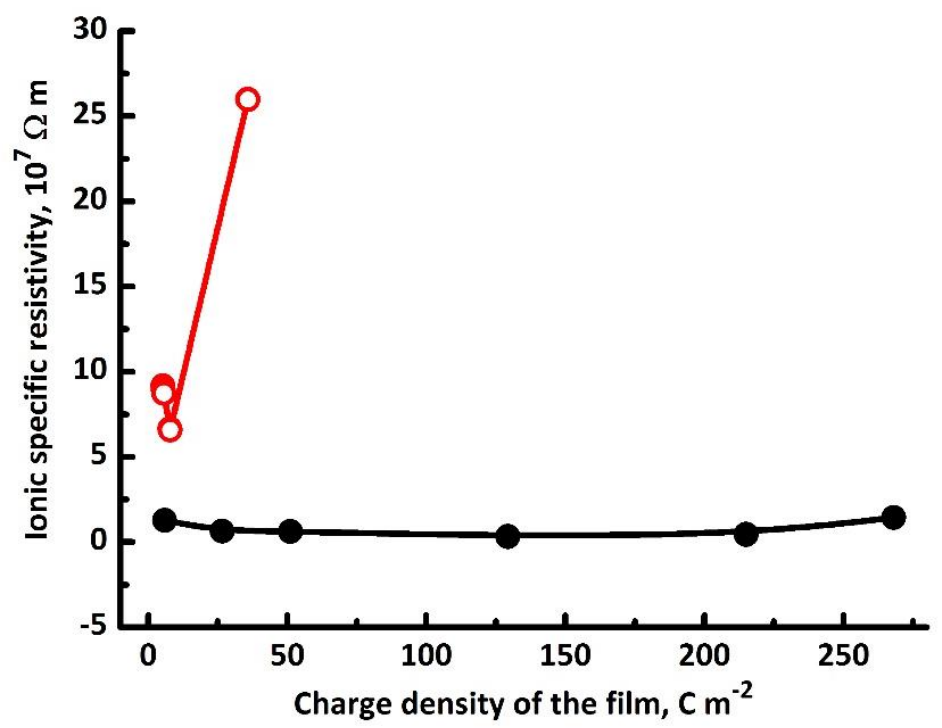

Figure 12. Ionic specific resistivity vs. charge density of the film for sweep rate equal to $2 \mathrm{mV} \mathrm{s}^{-1}$, for tin in borate solution (०) and for tin in phosphate solution (•). 
It is interesting to notice that the ionic specific resistivities for oxide film grown in borate solution are significantly higher than in phosphate solution. This result indicates that incorporation of anions probably occurs in the films during their growth leading to changes in ionic specific resistivities. Considering Eq. (4), it is possible to verify that this difference is a consequence of higher $\eta_{f}$ and lower $\mathrm{j}$ values in the voltammetry in borate solution. Differences in film densities and $V_{\mathrm{f}}$, in the two studied solutions, do not significantly determine the different values of ionic specific resistivities.

\section{Conclusions}

The application of the ohmic model and ellipsometric measurements in the voltammetric growth of tin oxides in borate solution $\mathrm{pH} 8.7$ turned possible to verify that:

- There are no significantly differences between the kinetics in the metal/film interface of tin in borate and tin in phosphate solutions. This conclusion was supported by the obtained values of $j_{\mathrm{m} / \mathrm{f}}^{0}$ and $\alpha$ in both cases.

- The values of $V_{f}$ significantly decrease until $50 \mathrm{C} \mathrm{m}^{-2}$ of charge density of the film is achieved approximating the values of $\mathrm{V}_{\mathrm{f}}$ considering $\mathrm{SnO}$ and $\mathrm{SnO}_{2}$. This result shows that the film is less dense for lower values of charge density and becomes denser as the thickness increases.

- The ionic specific resistivities for oxide film grown in borate solution are significantly higher than in phosphate solution at $2 \mathrm{mV} \mathrm{s}^{-1}$. This result indicates that incorporation of anions probably occurs in the films during their growth, which leads to changes in ionic specific resistiveties, contributing to different values of $\eta_{\mathrm{f}}$ and consequently different voltammograms.

Acknowledgements: The author (Tiago Brandão Costa) is grateful to CAPES for his Doctor fellowship. The authors are grateful to Programa de Pós-Graduação em Engenharia Metalúrgica (PPGEM), Escola de Engenharia Industrial Metalúrgica de Volta Redonda (EEIMVR), Universidade Federal Fluminense (UFF) for the opportunity of realizing this work, making the Laboratory of Electrochemical available.

\section{Notation}

A electrode surface area, $\mathrm{m}^{2}$

$b_{\text {a }}$ Tafel slope

$E$ potential, $\mathrm{V}$

$E_{\mathrm{F}}$ Flade potential, $\mathrm{V}$

$E_{\mathrm{m} / \mathrm{f}}$ potential at the metal/film interface, $\mathrm{V}$

$F \quad$ Faraday's constant, $\mathrm{C} \mathrm{mol}^{-1}$

$j$ current density, $\mathrm{A} \mathrm{m}^{-2}$

$j_{p} \quad$ current density at the voltammetric peak, $\mathrm{A} \mathrm{m}^{-2}$

$j_{\mathrm{m} / \mathrm{f}}^{0}$ exchange current density at zero $\eta_{\mathrm{m} / \mathrm{f}}, \mathrm{A} \mathrm{m}^{-2}$

$\ell$ thickness of oxide layer, $m$

$M$ molar mass of the film, $\mathrm{kg}$

$n$ number of electrons

$q_{\mathrm{f}}$ charge density of the film, $\mathrm{C} \mathrm{m}^{-2}$

$q_{0}$ charge density related to the amount of film initially present, at the beginning of the voltammetric growth on the metal surface, $\mathrm{C} \mathrm{m}^{-2}$

$q_{\text {volt }}$ charge density related to the amount of film which has grown during voltammetric experiment, $\mathrm{C} \mathrm{cm}^{-2}$

$q_{\mathrm{f}, \mathrm{p}}$ peak or plateau charge density, $\mathrm{C} \mathrm{cm}^{-2}$

$R \quad$ gas constant, $8.314 \mathrm{~J} / \mathrm{mol} \mathrm{K}$

SE spectroscopic ellipsometry

$T$ temperature, $\mathrm{K}$

$V_{\mathrm{f}} \quad$ volume per charge unit, $\mathrm{m}^{3} \mathrm{C}^{-1}$

$\alpha_{a}$ anodic transfer coefficient 
$\alpha_{c} \quad$ cathodic transfer coefficient

$\delta$ density of the film, $\mathrm{kg} \mathrm{m}^{-3}$

$\eta_{\mathrm{m} / \mathrm{f}}$ overpotential at the metal/film interface

$\eta_{\text {f.p }}$ overpotential across the film at the voltammetric peak

$\eta_{f}$ overpotential across the film

$v$ sweep rate, $\mathrm{V} \mathrm{s}^{-1}$

$\rho_{\mathrm{f}} \quad$ ionic specific resistivity of the film, $\Omega \mathrm{m}$

\section{References}

[1] H. Do Duc, P. Tissot, Corrosion Science 19 (1979) 179-190.

[2] S. D. Kapusta, N. Hackerman, Electrochimica Acta 25 (1980) 1625-1639.

[3] S. D. Kapusta, N. Hackerman, Electrochimica Acta 25 (1980) 949-955.

[4] S. D. Kapusta, N. Hackerman, Electrochimica Acta 25 (1980) 1001-1006.

[5] S. D. Kapusta, N. Hackerman, Electrochimica Acta 25 (1982) 1886-1889.

[6] A. Ammar, S. Darwish, M. W. Khalil, S. El-Taher, Electrochimica Acta 33 (1988) 231-238.

[7] M. Metikos-Hukovic, M. Seruga, F. Ferina, Ber. Bunsenges Phys. Chem 96 (1992) 799-805.

[8] M. Metikos-Hukovic, A. Resetic, V. Gvozdic, Electrochimica Acta 40 (1995) 1777-1779.

[9] C. A. Gervasi, P. E. Alvarez, Corrosion Science 47 (2005) 69 -78.

[10] V. Brunetti, M. L. Teijelo, Journal of Electroanalytical Chemistry 613 (2008) 9-15.

[11] N. A. Al-Mobarak, Chemistry and Technology of Fuels and Oils 48 (2012) 321-330.

[12] T. B. Costa, T. M. C. Nogueira, L. Silva, Journal of Electrochemical Science and Engineering. 6 (2016) 303-314.

[13] C. V. D’Alkaine, P. C. Tulio, M. A. C. Berton, Electrochimica Acta 49 (2004) 1989-1997.

[14] C. V. D'Alkaine, L. M. N. Souza, F. C. Nart, Corrosion Science 34 (1993) 129-149.

[15] C. V. D'Alkaine, M. N. Boucherit, Journal of the Electrochemical Society 10 (1997) 33313336.

[16] C. V. D'Alkaine, M. A. Santanna, Journal of Electroanalytical Chemistry 457 (1998) 13-21.

[17] T. B. Costa, C. V. D'Alkaine, T. M. C. Nogueira, $67^{\text {th }}$ ABM International Congress, Rio de Janeiro, Brazil, 2012, p. 3162.

[18] R. Díaz, I. Díez-Pérez et al, Journal of Brazilian Chemical Society 14 (2003) 523-529.

[19] M. Hernández Ubeda, M.A.Pérez et al, Journal of the Electrochemical Society 152(1) (2005) A37-A41.

[20] Z. Szklarska-Smialowska, W. Kozlowski, Journal of the Electrochemical Society 131 (1984) 499-505.

[21] H. Fujiwara, Spectroscopic Ellipsometry: Principles and Applications. John Wiley \& Sons Ltd, Tokyo, Japan, 2003.

[22] L. F. N. Guedes et al, Journal of Solid State Electrochemistry 20 (2016) 2517-2523.

[23] W. Kozlowski, J. Flis, Corrosion Science 32 (1991) 861-875.

[24] D. E. Aspnes, Thin Solid Films 571(3) (2014) 334-344.

[25] A. J. Bard and L. R. Faulkner, Electrochemical Methods Fundamentals and Applications, John Wiley \& Sons, New York, United States, 2001.

C2017 by the authors; licensee IAPC, Zagreb, Croatia. This article is an open-access article distributed under the terms and conditions of the Creative Commons Attribution license (http://creativecommons.org/licenses/by/4.0/) 